\title{
Spectroscopic and calorimetric studies of congo red dye-amyloid $\beta$ peptide complexes
}

\author{
Kazushige Yokoyama ${ }^{1 *}$, Andrew D. Fisher ${ }^{1}$, Amanda R. Amori ${ }^{1}$, Daniel R. Welchons ${ }^{2}$, \\ Ruel E. McKnight ${ }^{1^{*}}$ \\ ${ }^{1}$ Department of Chemistry, State University of New York at Geneseo, One College Circle, Geneseo, USA; \\ ${ }^{2}$ Brigham and Women's Hospital, Harvard Medical School, Boston, USA; *Corresponding Author: yokoyama@geneseo.edu; \\ mcknight@geneseo.edu
}

Received 15 September 2010; revised 18 October 2010; accepted 23 October 2010.

\section{ABSTRACT}

Thermodynamic properties of complexes of Congo Red (CR) dye with amyloid $\beta$ (A $\beta$ ) peptides were studied by both absorption spectroscopy and isothermal titration calorimetry (ITC). Based on the absorption spectrum for the formation of CR-A $\beta$ complexes in phosphate buffered saline solution ( $\mathrm{pH}$ 7.4), van't Hoff plots over a temperature range of $10^{\circ} \mathrm{C}$ to $70^{\circ} \mathrm{C}$ were created for $C R-A \beta_{1-40},-A \beta_{12-28}$, and $-A \beta_{1-42}$. The plot for $C R$ $A \beta_{12-28}$ complex showed a relatively linear feature within the given temperature range with $\Delta \mathrm{H}=$ $-10.1 \pm 0.6 \mathrm{~kJ} / \mathrm{mol}$ and $\Delta S=+0.128 \pm 0.002$ $\mathrm{kJ} /(\mathrm{mol} \mathrm{K})$. However, the plot for CR-A $\beta_{1-40}$ and $C R-A \beta_{1-42}$ complexes exhibited two distinct linear regions with opposite slopes centered at a specific temperature, $T_{s}$, which was $54.7 \pm 0.2^{\circ} \mathrm{C}$ and $34.8 \pm 0.2^{\circ} \mathrm{C}$, respectively. The ITC experiments conducted at $25^{\circ} \mathrm{Cin}$ water exhibited quite a different situation from the above mentioned spectroscopic approach. The ITC studies yielded a $\Delta H$ of $-85.3 \pm 0.2 \mathrm{~kJ} / \mathrm{mol}$ for the CR-A $\beta_{12-28}$ complex with negative entropy change $-0.152 \mathrm{~kJ} / \mathrm{mol} \mathrm{K}$ ). For CR-A $\beta_{1-40}$, the ITC studies indicated the presence of two binding sites with $\Delta \mathrm{H}_{1}=-81.8 \pm$ $0.3 \mathrm{~kJ} / \mathrm{mol}$ and $\Delta \mathrm{H}_{2}=-119.5 \pm 0.2 \mathrm{~kJ} / \mathrm{mol}$ with $\mathrm{K}_{1}=$ $5.5 \pm 0.7 \times 10^{6} \mathrm{M}^{-1}$ and $\mathrm{K}_{2}=6.9 \pm 2.4 \times 10^{8} \mathrm{M}^{-1}$, respectively. These binding constants are consistent with the model suggested by several studies. Both binding sites showed negative entropy changes suggesting that the formation of the complex is enthalpically driven. The disagreement in thermochemical values between two different methods confirmed that the enthalpy and entropy are heavily dependent on temperature and buffer/salt environment, and may in- volve inherently different reaction paths.

Keywords: Amyloid Beta; Congo Red Dye-Protein Interaction; Van't Hoff Plot; Isothermal Titration Calorimetry; Binding Site; Temperature Dependence; UV-Vis Absorption Spectroscopy

\section{INTRODUCTION}

Pathologically, a key hallmark of Alzheimer's disease (AD) is the formation of insoluble fibrillar deposits of amyloid $\beta$-peptide $(\mathrm{A} \beta)$ as both diffuse and senile amyloid plaques invade the brains seat of memory and cognition (brain parenchyma and vasculature) before spreading to other areas [1-3]. While senile plaques comprise clusters of $A \beta$-fibrils surrounded by dead and dying neurons and reactive astrocytes and microglial cells [4], diffuse plaques are composed of predominantly amorphous $A \beta$ and may contain a small population of $A \beta$ fibrils [5]. All amyloid fibril-related diseases shares the presence of amyloid fibrils leading to protofibrillar species as the primary sources of toxicity [6-13].

The main components of the neuritic and cerebrovascular amyloid in $\mathrm{AD}$ are the 42 and 40 residue $\mathrm{A} \beta, \mathrm{A} \beta_{1-42}$ and $A \beta_{1-40}$, respectively $[14,15]$. In order to rationally design an effective therapeutic agent, knowledge of the interactions involving the early ordered oligomers at the molecular level is critical. These fibrillar and protofibrillar species typically have large surface available for binding, while the interactions between ligand and different aggregate species are hard to differentiate [16]. If $\mathrm{A} \beta_{1-40}$ has a sensitive response to the different degree of binding interaction, it may be able to prevent aggregation by manipulating the types of interactions adopted by the $A \beta_{1-40}$ monomer. This is especially important in the molecular mechanisms of binding between (weak) inhibitors and the protofibrillar oligomers which allowed 
us to understand the surface property of the peptide oligomers.

In this regard, Congo Red (CR) has been identified as a key inhibitor which reduce the neurotoxicity of AD by binding to protofibrils [11], and this inhibitory activity of $\mathrm{CR}$ and its derivatives have been screened as potential therapeutics against amyloid fibril formation [17-20]. The apolar moiety of CR is comprised of a biphenyl group at the center of the molecule and is extended by a diazo and two naphthalene groups. (Figure 1) The polar amino group and the negatively charged sulfonate group are linked to a naphthalene ring. CR binds to amyloid fibrils formed by both hydrophobic and hydrophilic interactions [21,22]. Several studies have indicated that certain specific segments of $A \beta$ monomer are critical for binding to CR. These segments are located between sequences 17 and [22,23]. (See Figure 2)

Recently, Yokoyama et al. has found that $\mathrm{A} \beta$ monomers behave differently when they are conjugated on the nano gold surface as compared to when they are dispersed in the solution [24-28]. These studies indicated that the $A \beta$ monomers are involved in nanosize dependent self-assembly over the nanoscale surface while a portion of $\mathrm{A} \beta$ monomer segments is conjugated on the gold surface. This result implied that the entire segments of $A \beta$ monomer (1-40 or 1-42 sequences) can be divided into at least two major segments, where one section is responsible for the conjugation while the other is responsible for the self-assembly. Recent investigation also revealed a unique temperature dependence in self- assembly over nanoscale surface, where $\beta$-sheet involved self-assembly was enhanced at lower temperatures. This is in stark contrast to the situation in solution where $\beta$-sheet was preferably produced at the higher temperature [28]. This observation implies that the self assembly of $A \beta$ involved in conjugation must provide quite different thermochemistry than those dispersed in solution. Furthermore, inhibitors of self-assembly, such as $\mathrm{CR}$, are speculated to bind much stronger by electrostatic interaction allowing the inhibition to overrule the self-assembly process.

In this report, additional insight into the interaction between $A \beta$ peptide and CR are provided. Herein, the critical thermochemical parameters involved in the complex formation between $\mathrm{A} \beta$ and $\mathrm{CR}$ are reported. These parameters are extracted using spectroscopic methods covering a broad temperature range, as well as by isothermal titration calorimetry (ITC) experiments at a specific temperature $\left(25^{\circ} \mathrm{C}\right)$. This study aims to confirm whether $\mathrm{CR}$ dye has more than one binding site when bound to $A \beta_{1-40}$ and to clarify the role of the network composed of an entire $A \beta_{1-40}$ in complexation with $\mathrm{CR}$ by comparing the

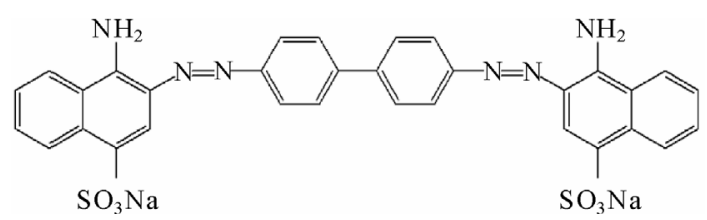

Figure 1. The molecular structure of CR (Congo Red) dye.
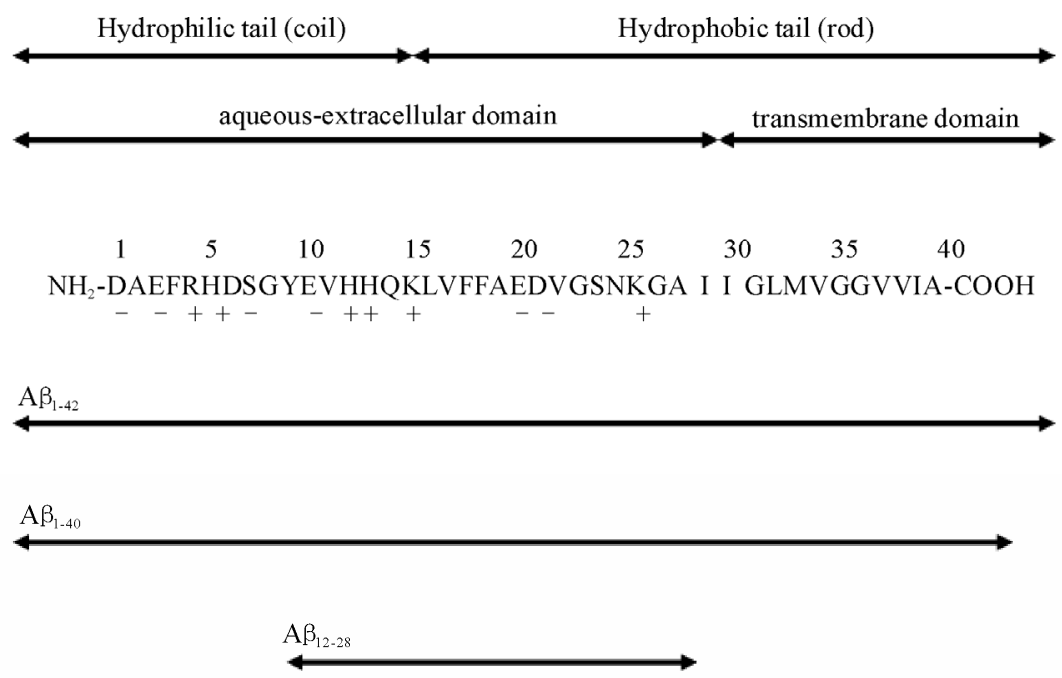

Figure 2. The entire sequences of $A \beta$ studied in this work. The charges $(+$ or -$)$ at neutral $\mathrm{pHs}$ are given beneath the sequences. Hydrophobic residues are given in bold letters. The sequences in which thermal properties were determined are indicated by double sided arrows with solid lines, whereas those that did not dissolve in PBS are shown with double sided arrows with dotted lines. 
complex formation with the central segment of the peptide chain, i.e., $\mathrm{A} \beta_{12-28}$.

\section{MATERIALS AND METHODS}

All $A \beta$ proteins used in this project were obtained from American Peptide Co. (Sunnyvale, CA USA), and were: $\mathrm{A} \beta_{12-28} \quad[\mathrm{MW}: 1955.2], \mathrm{A} \beta_{1-40}[\mathrm{MW}: 4329.9]$, and $\mathrm{A} \beta_{1-42}$ [MW:4514.1]. The ultra-pure $A \beta$, in the form of lyophilized powder ( $97 \%$ by HPLC) was stored at $-20^{\circ} \mathrm{C}$ in a desiccated-vacuumed container. The stock solution $(\mathrm{A} \beta 100 \mu \mathrm{M})$ was prepared using double-distilled, deionized, and filtered water, and then vortex mixed for 60 seconds. In this experiment, protein was gel-filtered, the monomeric species was collected and analyzed immediately by $\mathrm{CD}$ and UV-Vis spectrometer. For the samples used for absorption spectroscopy, degassed phosphatebuffered saline (PBS) $\mathrm{pH}=7.4$ (Sigma Life Science, St. Louise, MO USA) was added for the dilution to $10 \mu \mathrm{M}$ peptide concentration. The congo red dye (CR), sodium 3,3'-(1E,1'E)-iphenyl-4, '-diylbis diazene-2, -diyl) bis (4-aminonaphthalene-1-sulfonate), was obtained from Sigma Life Science, St. Louise, MO USA. The CRsolution was directly dissolved into PBS and filtered three times using cellulose acetate membrane filter (pore size $0.45 \mu \mathrm{m})$. The CR solution was then stored at room temperature in order to prevent precipitation and aggregation. However, it should be noted that the collection of the isothermal titration calorimetry (ITC) data was not successful in buffer solution despite many attempts using various phosphate buffer concentrations. Therefore, $\mathrm{A} \beta$ was directly dissolved in water for the ITC experiment.

Spectrophotometry: Absorption spectra were collected by a HP-Diode Array Spectrophotometer (HP8452A) with a UV-enhanced quartz cuvette cell. The temperature control of the absorption cell was conducted by a feedback loop-temperature control system with the glycol as a heating or cooling media. The temperature of the solution was directly measured by a digital thermometer, and was maintained within $\pm 0.2^{\circ} \mathrm{C}$ of accuracy for each measurement for the range between 10 and $70^{\circ} \mathrm{C}$. The concentration of $\mathrm{CR}$ stock solution was determined by a molar absorptivity value for $\mathrm{CR}$ in $40 \%$ ethanol of 5.93 $\times 10^{4} \mathrm{AU} /(\mathrm{cm} \mathrm{M})$. [21] The experiment was conducted at a peptide concentration of around $10 \mu \mathrm{M}$, which is less than a critical concentration range $\left(4 \times 10^{-6} \mathrm{M}\right)$ for fibrillogenesis of $A \beta_{1-40}$ [29-31] with $2 \times 10^{-6} \mathrm{M} C R$. The concentration of all $A \beta$ were confirmed by the UV absorbance of tyrosine at $275 \mathrm{~nm}\left(\varepsilon_{275}=1390 /(\mathrm{cmM})\right)$ [32].

Isothermal titration calorimetry (ITC): Calorimetric titrations were carried out on a MicroCal VP-ITC (Mi-
croCal Inc., Northampton, MA). The data was analyzed using the Origin 7.0 software. All experiments were run at $25^{\circ} \mathrm{C}$ in deionized water, and exactly $10 \mu \mathrm{l}$ of CR solution $\left(7.0 \times 10^{-5} \mathrm{M}\right)$ was injected into $1.4 \mathrm{ml}$ of amyloid $\beta$-peptide $\left(\mathrm{A} \beta_{1-40}\right.$ or $\left.\mathrm{A} \beta_{12-28}, 2.5 \times 10^{-5} \mathrm{M}\right)$ over $20 \mathrm{~s}$ at $240 \mathrm{~s}$ intervals using a $250 \mu \mathrm{l}$ syringe rotating at 307 rpm. Samples were degassed at $25^{\circ} \mathrm{Cusing}$ a ThermoVac apparatus (MicroCal) before use. Each peak corresponded to the decrease in the power supplied to keep the temperatures of the sample and reference cells the same for each injection and represents the heat given off. In each case, response signals were corrected for the small heat of dilution associated with titrating the CR solution into water. The heat of dilution for titrating water into the peptide was negligible. A binding isotherm of heat released as a function of the $\mathrm{CR} / \mathrm{A} \beta$-peptide molar ratio was constructed and the data fitted by nonlinear least square fitting analysis.

Gel electrophoresis: Polyacrylamide gel electrophoresis (PAGE) of congo red (CR) binding to $A \beta_{1-40}(2.8 \mathrm{x}$ $10^{-5} \mathrm{M}$ ) were conducted in plain water and in phosphate buffered saline (PBS) buffer, $\mathrm{pH}$ 7.4. Increasing amounts of congo red solution was added to $A \beta_{1-40}$ and the mixture allowed 15 minutes for complexation. The CR: $\mathrm{A} \beta_{1-40}$ ratios were as follows: $1: 10,1: 5,1: 2.5$, and 1:1.3 in water, and 1:20, 1:10, 1:5, 1:2.5 in PBS buffer. PAGE was then run at $120 \mathrm{~V}$ for $3 \mathrm{hrs}$ using a Mini-PROTEAN 3 electrophoresis system (Bio-Rad). The samples were then stained and destained using Coomassie Brilliant Blue R-250 staining and destaining solutions (Bio-Rad), respectively.

The electrophoresis experiments of CR-A $\beta$ complexes were conducted in an effort to detect the presence of different aggregate forms over the $\mathrm{CR} / \mathrm{A} \beta$ ratios (gel figure not shown). No difference in the species present neither over the range of CR:A $\beta$, nor in the different solvent (water or PBS) were observed, verifying that method-specific differential aggregation does not contribute significantly to the observations of this study. Results using TEM [26] or AFM [27] from earlier reports by Yokoyama et al also confirmed that no aggregates of the $\mathrm{A} \beta_{1-40}$ monomers were formed under $\mathrm{pH} 7$.

\section{RESULTS}

\subsection{Spectroscopic Investigation}

The absorption spectra of $\mathrm{CR}$ solution, $\mathrm{CR}-\mathrm{A} \beta_{1-40}$, and $\mathrm{CR}-\mathrm{A} \beta_{1-42}$ mixtures are shown in Figure 3. The spectrum of CR-A $\beta_{12-28}$ was very similar to that of CR-A $\beta_{1-40}$. The band originating from the CR-alone possesses absorption peaks around $350 \mathrm{~nm}\left(\pi-\pi^{*}\right.$ transition of $-\mathrm{NH}$ group) and around $480 \mathrm{~nm}$ ( $\pi-\pi^{*}$ transition of azo group). These bands' intensity increased and shifted to 300 and 


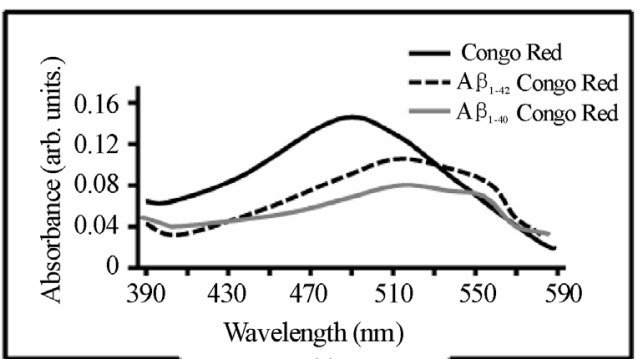

(a)

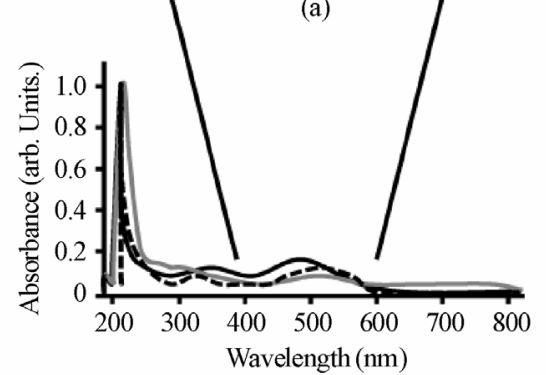

(b)

Figure 3. The absorption spectra of $C R$ and $A \beta_{1-40}$ and $\mathrm{A} \beta_{1-42}$ mixtures in (a) $400-600 \mathrm{~nm}$ region and (b) 200-800 nm region.

$540 \mathrm{~nm}$, respectively, as the concentration of the $\mathrm{A} \beta$ fibrils increased [21]. While it exhibited the band as a shoulder between the 240-280 $\mathrm{nm}$ range, this was also attributed to a CR-A $\beta$ complex. The bands featured in the 400-600 $\mathrm{nm}$ region were investigated in this study since the bands were more clearly identified. Particularly at the lower temperature, the $\mathrm{CR}$ and $\mathrm{A} \beta_{1-42}$ mixture exhibited insoluble aggregates dispersed in the cell, while the rest of the CR-A $\beta$ exhibited no precipitations. The scattering signal due to the precipitates was anticipated to appear in the region between 300 and $800 \mathrm{~nm}$ with relatively weak intensity compared to that by $\mathrm{CR}-\mathrm{A} \beta$ complex. The scattered signal was subtracted to glean an accurate concentration of the CR-A $\beta$ complex.

The concentration of the CR-A $\beta$ complex $[C R-A \beta]$ at a given temperature, $\mathrm{T}$, was calculated by the molar extinction coefficient $(\varepsilon)$, using the scattering signal formula reported by Klunk et al as:

$$
[C R-A \beta]_{T}=\frac{\left\{\frac{A(\text { total })_{T}^{541}}{\varepsilon(\text { free }-C R)_{T}^{541}}-\frac{A(\text { total })_{T}^{403}}{\varepsilon(\text { free }-C R)_{T}^{541}}\right\}}{\left\{\frac{\varepsilon(\text { bound })_{T}^{541}}{\varepsilon(\text { free }-C R)_{T}^{541}}-1\right\}}
$$

The superscripts show the wavelength at which the absorbance or extinction coefficient was measured, and the contents are shown inside the parentheses. The molar absorption, A, at given wavelength $(\lambda)$ and temperature (T) were given by

$$
\begin{aligned}
& A(\text { total })_{T}^{\lambda}=A(\text { bound }-C R)_{T}^{\lambda}+A(\text { free }-C R)_{T}^{\lambda} \\
& =\varepsilon(\text { bound }-C R)_{T}^{\lambda}+\varepsilon(\text { free }-C R)_{T}^{\lambda}
\end{aligned}
$$

The absorbance of free CR was obtained from separate measurements of $\mathrm{CR}$ solution alone for a specific

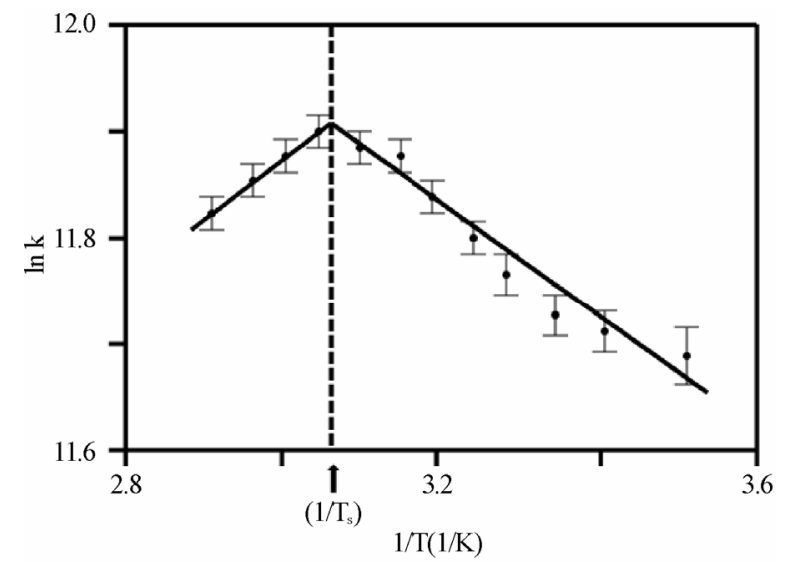

(a) $\mathrm{CR}-\mathrm{A} \beta_{1+1,0}$

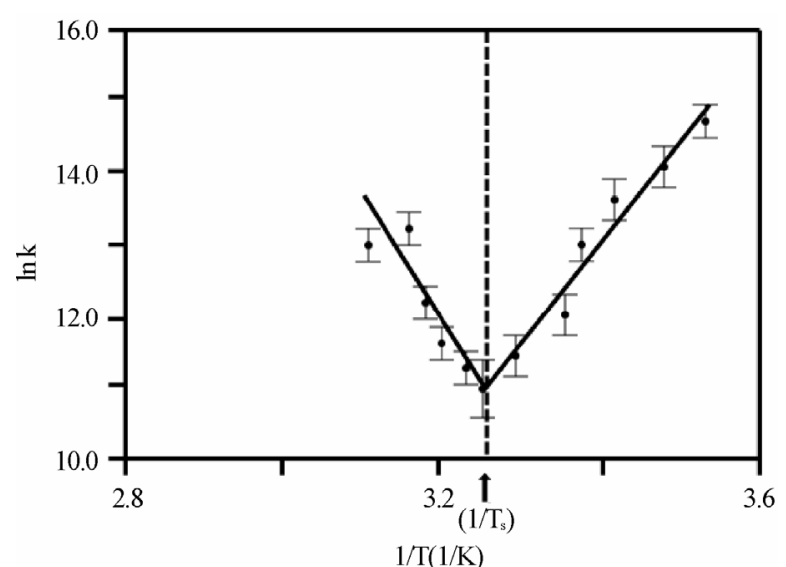

(b) $\mathrm{CR}-\mathrm{A} \beta_{1+42}$

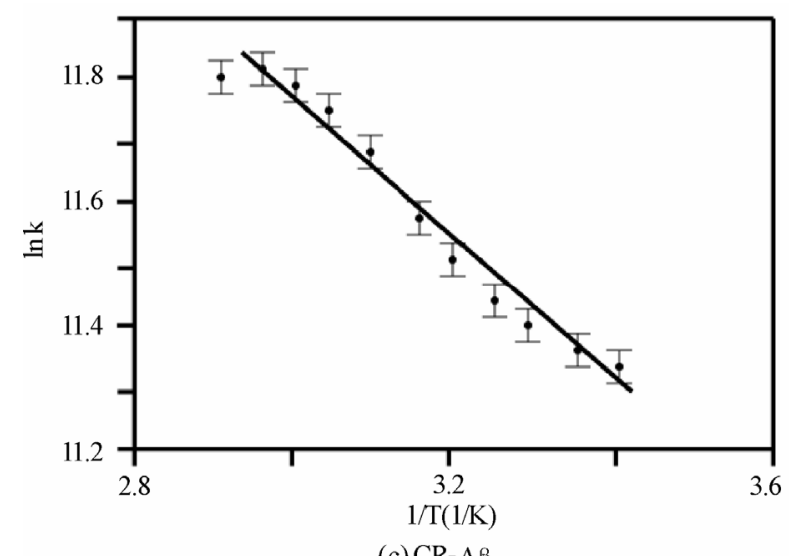

(c) $\mathrm{CR}-\mathrm{A} \beta_{1228}$

Figure 4. The van't Hoff plot (ln $\mathrm{K}$ vs. $1 / \mathrm{T} \times 10^{3}[1 / \mathrm{K}]$ ) for (a) $\mathrm{CR}-\mathrm{A} \beta_{1-40}$, (b) CR-A $\beta_{1-42}$, and (c) CR-A $\beta_{12-28}$. The solid lines are reproduced by the van't Hoff plot. 
change by a Boltzmann distribution at different tem temperature in order to calibrate the thermal population peratures. The temperature dependence of the absorption extinction coefficient of $\mathrm{CR}$ alone was first explored between 10 to $70^{\circ} \mathrm{C}$.

Once the concentration of the complex was determined the concentration of $\mathrm{A} \beta,[\mathrm{A} \beta]_{\mathrm{T}}$, and $\mathrm{CR},[\mathrm{CR}]_{\mathrm{T}}$, at a temperature, $\mathrm{T}$, could be given by

$$
\begin{aligned}
& {[A \beta]_{T}=[A \beta]_{o, T}-[C R-A \beta]_{T}} \\
& {[C R]_{T}=[C R]_{o, T}-[C R-A \beta]_{T}}
\end{aligned}
$$

where $[A \beta]_{0, T}$ and $[C R]_{0, T}$ indicate initial concentrations of $A \beta$ and $C R$ at a given temperature $(T)$, respectively.

A simplified equilibrium model of the complex formation reaction can be given as:

$$
\mathrm{A} \beta+\mathrm{CR} \rightleftarrows \mathrm{CR}-\mathrm{A} \beta
$$

The equilibrium constant, $\mathrm{K}$, at each temperature at $\mathrm{T}$ was given by:

$$
K_{T}=\frac{[C R-A \beta]_{T}}{[A \beta]_{T}[C R]_{T}}
$$

The validity of the expression of the equilibrium constant was confirmed by variations of each component of concentration and its corresponding shift in $\mathrm{K}_{\mathrm{T}}$ values. The van't Hoff plot:

$$
\ln K_{T}=\frac{\Delta S}{R}-\frac{\Delta H}{R T}=\frac{1}{R}\left(\Delta S-\frac{\Delta H}{T}\right)
$$

was adopted to extract entropy change $(\Delta S)$ and enthalpy change $(\Delta \mathrm{H})$ assuming these values are weakly dependent on a given temperature range. Generally, the thermal features provided by the van't Hoff plot were distinct for each CR-A $\beta$ complex as seen in Figures 4(a), 4(b), and 4(c). The values predicted by the Eq.6 were reproduced by a solid line in the figures when appropriate. Within the observed temperature range, the thermal property of the CR-A $\beta_{12-28}$ mixture followed a feature explained by the van't Hoff plot in the entire temperature range of this study. In contrast, the plot for the CR- $A \beta_{1-40}$ and CR-A $\beta_{1-42}$ clearly showed two separate linear regions with mutually opposite phases of slopes (i.e., different signs in $\Delta \mathrm{H})$.

For limiting linear regions, the data was analyzed by Eq.6 assuming standard enthalpy of formation $\left(\Delta \mathrm{H}^{\circ}\right)$ and the standard entropy change $\left(\Delta \mathrm{S}^{\circ}\right)$ does not depend on the temperature in the observed region. For the case of the temperature region involving $25^{\circ} \mathrm{C}$, the Gibbs energy change, $\Delta \mathrm{G}^{\circ}$ at $25^{\circ} \mathrm{C}$ was calculated by using the $\Delta \mathrm{S}^{\mathrm{o}}$ and $\Delta \mathrm{H}^{\mathrm{o}}\left(\Delta \mathrm{G}^{\mathrm{o}}=\Delta \mathrm{H}^{\mathrm{o}}-\mathrm{T} \Delta \mathrm{S}^{\mathrm{o}}\right.$, where $\mathrm{T}=25^{\circ} \mathrm{C}$ $(298.15 \mathrm{~K})$ and at $1 \mathrm{~atm}$ of pressure) and the extracted values are tabulated in Table 1. However, in the regions which do not include $\mathrm{T}=25^{\circ} \mathrm{C}$, the averaged temperature in a particular region was used and the corresponding $\Delta \mathrm{G}$ was calculated. This region is a positive slope region for CR-A $\beta_{1-40}$ complex which exists over $\mathrm{T}_{\mathrm{S}}=$ $54.7^{\circ} \mathrm{C}$ and a negative slope region over $\mathrm{T}_{\mathrm{S}}=34.8^{\circ} \mathrm{C}$ for $\mathrm{CR}-\mathrm{A} \beta_{1-42}$. The average temperature used for this region was $62.5 \pm 0.2{ }^{\circ} \mathrm{C}$ and $52.5 \pm 0.2{ }^{\circ} \mathrm{C}$ for $\mathrm{CR}-\mathrm{A} \beta_{1-40}$ and $\mathrm{CR}-\mathrm{A} \beta_{1-42}$ complex, respectively. When a plot contained two different linear regions, both regions were utilized to obtain the final values separately. The temperature at which the linear slope switches its slope is shown as a specific temperature, $T_{s}$, in Table 1.

\subsection{ITC Investigation}

The ITC data obtained for $A \beta_{1-40}$ and $A \beta_{12-28}$ with $C R$ dye in aqueous solution at $25^{\circ} \mathrm{C}$ is shown in Figures $5 \mathrm{~A}$ and $\mathrm{A} \beta+\mathrm{CR} \rightleftarrows \mathrm{CR}-\mathrm{A} \beta$, and the extracted thermochemical values for both complexes are tabulated in Table 2. Due to the highly hydrophobic nature of $A \beta_{1-42}$, preparation of a purely aqueous solution was not possible. As a result, ITC studies were not conducted with $\mathrm{A} \beta_{1-42}$. In the aqueous solution, the background heat of dilution obtained for titrating CR into water showed only endothermic signals that were comparably small and

Table 1. Summary of thermochemical values of CR-A $\beta$ complexes measured between 10 and $70^{\circ} \mathrm{C}$. The corresponding thermochemical values for $\mathrm{CR}-\mathrm{A} \beta_{22-35}$ mixture were not obtained. For the regions where $\mathrm{T}=25^{\circ} \mathrm{C}$, the $\Delta \mathrm{G}$ was obtained at $\mathrm{T}=25^{\circ} \mathrm{C}$. For the regions that do not include $\mathrm{T}=25^{\circ} \mathrm{C}$, the average temperature $\left(\mathrm{T}_{\text {avg }}\right)$ was used for calculating $\Delta \mathrm{G}$.

\begin{tabular}{lcccc}
\hline \multicolumn{1}{c}{ Sequence } & $\Delta \mathbf{H}^{\mathbf{0}}(\mathrm{kJ} / \mathrm{mol})$ & $\Delta \mathbf{G}^{\mathbf{0}}(\mathrm{kJ} / \mathrm{mol})^{* *}$ & $\Delta \mathbf{S}^{\mathbf{0}}(\mathrm{kJ} / \mathrm{mol} \mathrm{K})$ & $\mathbf{T}_{\mathbf{s}}\left({ }^{\circ} \mathrm{C}\right)$ \\
\hline $\mathrm{A} \beta_{1-40}\left(>\mathrm{T}_{\mathrm{s}}\right)$ & $-4.8 \pm 0.3$ & $-29.1 \pm 0.3$ & $0.084 \pm 0.001$ & $54.7 \pm 0.2$ \\
$\mathrm{~A} \beta_{1-40}\left(T_{\text {avg }}=62.5 \pm 0.2^{\circ} \mathrm{C}\right)$ & $-4.8 \pm 0.3$ & $-33.0 \pm 0.3$ & $0.084 \pm 0.001$ & \\
${ }^{*,+} \mathrm{A} \beta_{1-40}\left(<\mathrm{T}_{\mathrm{s}}\right)$ & $4.2 \pm 0.4$ & $-29.1 \pm 0.4$ & $0.112 \pm 0.001$ & \\
${ }^{+} \mathrm{A} \beta_{1-42}\left(<\mathrm{T}_{\mathrm{s}}\right)$ & $-115 \pm 13$ & $-30 \pm 13$ & $-0.28 \pm 0.05$ & $34.8 \pm 0.2$ \\
${ }^{*} \mathrm{~A} \beta_{1-42}\left(>\mathrm{T}_{\mathrm{s}}\right)$ & $130 \pm 45$ & $115 \pm 45$ & $0.51 \pm 0.14$ & \\
${ }^{*} \mathrm{~A} \beta_{1-42}\left(T_{\text {avg }}=52.5 \pm 0.2^{\circ} \mathrm{C}\right)$ & $130 \pm 45$ & $113 \pm 45$ & $0.51 \pm 0.14$ & \\
${ }^{*,+} \mathrm{A} \beta_{12-28}$ & $10.1 \pm 0.6$ & -29.13 & $0.128 \pm 0.002$ & - \\
\hline
\end{tabular}

+ The values obtained in the temperature range including $25^{\circ} \mathrm{C}$; ${ }^{*}$ Thermodynamic values from negative slope on van't Hoff plot; ** Gibbs free energy taken at $\mathrm{T}=298.775 \mathrm{~K}\left(25.6^{\circ} \mathrm{C}\right)$. 


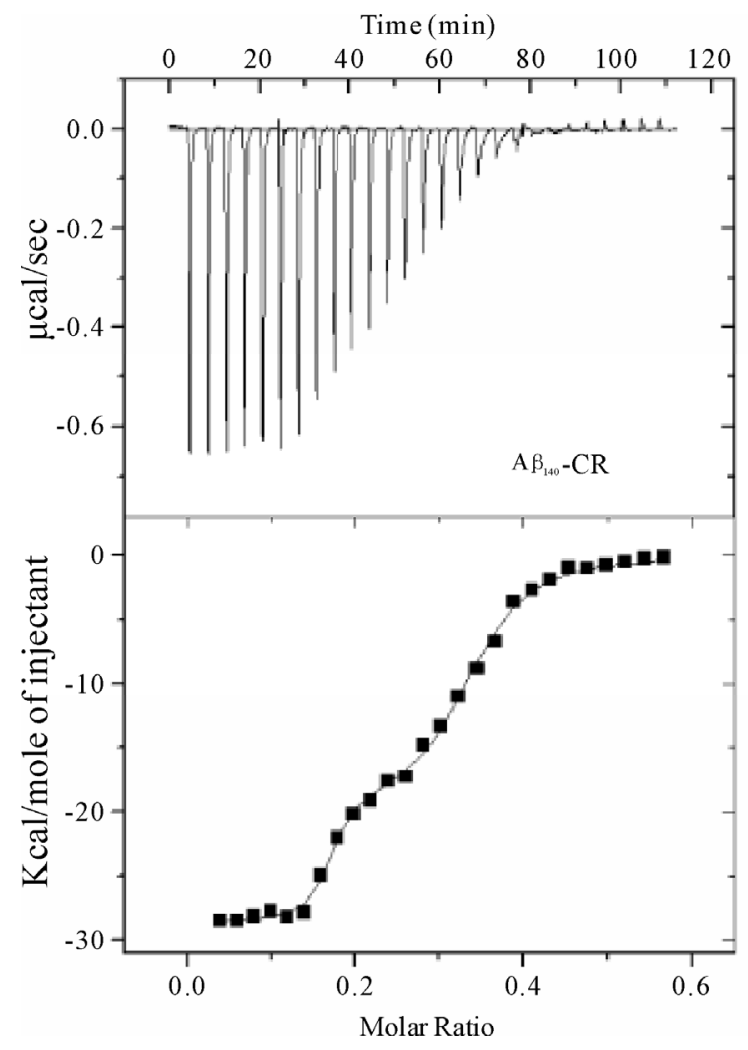

(a)

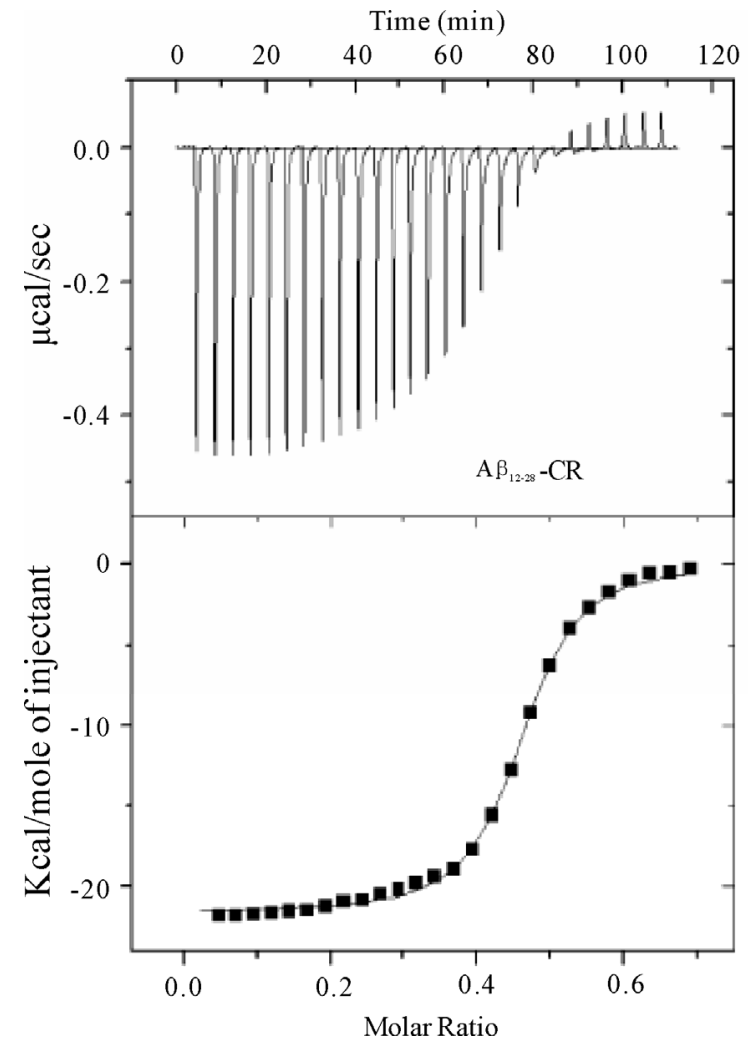

(b)

Figure 5. Calorimetric data (raw) for the titration of $C R\left(7 \times 10^{-5} \mathrm{M}\right)$ into a) $A \beta_{1-40}\left(2.5 \times 10^{-5} \mathrm{M}\right)$ and $\left.\mathrm{b}\right) \mathrm{A} \beta_{12-28}\left(2.5 \times 10^{-5}\right.$ $\mathrm{M})$ at $25^{\circ} \mathrm{C}$ (top panel). The binding isotherms (heat change vs $\mathrm{CR} / \mathrm{A} \beta$ molar ratio) were obtained from the integration of raw data and fitted to either a two-site $\left(\mathrm{A} \beta_{1-40}\right)$ or one-site $\left(\mathrm{A} \beta_{12-28}\right)$ model (bottom panel).

Table 2. Summary of thermochemical values of CR-A $\beta$ complexes measured by ITC at $25^{\circ} \mathrm{C}$. The two binding sites model was adopted for the CR-A $\beta_{1-40}$ complex.

\begin{tabular}{ccccc}
\hline Sequence & $\mathbf{K}\left(\mathbf{1 0}^{\mathbf{6}} \mathbf{M}^{-\mathbf{1}}\right)$ & $\begin{array}{c}\Delta \mathbf{H}^{\mathbf{0}} \\
(\mathrm{kJ} / \mathrm{mol})\end{array}$ & $\begin{array}{c}\Delta \mathbf{S}^{\mathbf{0}} \\
(\mathrm{kJ} / \mathrm{mol} \mathrm{K})\end{array}$ & $\begin{array}{c}\Delta \mathbf{G}^{\mathbf{0}} \\
(\mathrm{kJ} / \mathrm{mol})\end{array}$ \\
\hline $\mathrm{A} \beta_{1-40}$ & $5.5(0.7)$ & $-81.8(3)$ & -0.145 & -38.4 \\
& $692(245)$ & $-119.5(2)$ & -0.232 & -50.4 \\
$\mathrm{~A} \beta_{12-28}$ & $8.4(0.5)$ & $-85.3(2)$ & -0.152 & -40.1 \\
\hline
\end{tabular}

were subtracted from the signal caused by CR-A $\beta$ complexation. While runs in a buffered solution (sodium phosphate, $\mathrm{pH}$ 7.4) were attempted for both CR-A $\beta$ complexes, the results were inconclusive due to a combination of erratic and low calorimetric signals.

The ITC signals collected for the CR-A $\beta_{1-40}$ complex indicated a feature suggesting multiple componentswhen CR was titrated into $A \beta_{1-40}$ (Figure 5(a)), and this feature was found to be reproducible. The data was best explained by a two-site binding model with a higher $\left(\mathrm{K}_{2}\right.$ $\left.=6.9 \pm 2.4 \times 10^{8} \mathrm{M}^{-1}\right)$ and lower affinity $\left(\mathrm{K}_{1}=5.5 \pm 0.7\right.$ $\times 10^{6} \mathrm{M}^{-1}$ ) binding site as shown in Table 2 . As for the CR-A $\beta_{12-28}$ complex, the data was best explained by the single binding site model. Nonetheless, the feature of the signal was apparently different from that obtained for the $\mathrm{CR}-\mathrm{A} \beta_{1-40}$ complex indicating that the complexation is $\mathrm{A} \beta$ sequence dependent. The binding constant for $\mathrm{CR}$ $\mathrm{A} \beta_{12-28}$ complex took a value, $\mathrm{K}=8.4 \pm 0.5 \times 10^{6} \mathrm{M}^{-1}$, that was closer to the lower affinity binding site of the CR-A $\beta_{1-40}$ complex, suggesting that both binding site may have similar features. For both the CR-A $\beta_{1-40}$ and CR-A $\beta_{12-28}$ complexes, the enthalpy change showed highly negative values suggesting that the interaction was enthalpically driven, which was also indicated by the negative $\Delta \mathrm{S}$ values. The Gibbs energy value using the obtained $\Delta \mathrm{S}$ and $\Delta \mathrm{H}$ values at $25^{\circ} \mathrm{C}$ indicated that the formation of the CR-A $\beta_{1-40}$ complex is more spontaneous than that of CR-A $\beta_{12-28}$ based on the $\Delta \mathrm{G}$ values for the higher affinity site of CR-A $\beta_{1-40}$ complex.

\section{DISCUSSION}

\subsection{Temperature Dependence of $C R-A \beta$ Conformation}

The obtained thermal properties from van't Hoff plot 
for each complex (shown in Table 1) clearly showed $A \beta$-sequence dependence. Based on the Gibbs energy, the CR-A $\beta_{12-28}$ and $-A \beta_{1-40}$ complexes were concluded to be formed spontaneously under aqueous environment. As for the formation of CR-A $\beta_{1-42}$ complex, it exhibited significantly different thermal properties $(\Delta \mathrm{G} \sim+110$ $\mathrm{kJ} / \mathrm{mol}$ and $\Delta \mathrm{H} \sim 130 \mathrm{~kJ} / \mathrm{mol}$ ) than those obtained for CR$A \beta_{12-28}$ or $-A \beta_{1-40}$ complexes. These thermal values suggest that the bonds within hydrophobic segments of $\mathrm{A} \beta_{1-42}$ monomer (17-42) must be broken in order to arrange entire $A \beta_{1-42}$ to be more hydrophilic under an aqueous environment.

While both CR-A $\beta_{12-28}$ and $-A \beta_{1-40}$ complexes exhibited similar $\Delta \mathrm{G}$ values (c.a. $-30 \mathrm{~kJ} / \mathrm{mol}$ ), they possessed different enthalpy values, where $\Delta \mathrm{H}\left(\mathrm{CR}-\mathrm{A} \beta_{1-40}\right) \sim-5 \mathrm{~kJ} / \mathrm{mol}$ and $\left.\Delta \mathrm{H}\left(\mathrm{CR}-\mathrm{A} \beta_{12-28}\right) \sim 10 \mathrm{~kJ} / \mathrm{mol}\right)$ for most of the temperature range studied in this work. The CR-A $\beta_{12-28}$ complex must be formed by an entropy-driven process, where more structural change leading entropy increase under the formation of the complex was achieved. The CR-A $\beta_{12-28}$ complex can easily unfold to allow intercalation of the CR inside the chain leading to entropy increase. The van't Hoff plot for the CR-A $\beta_{12-28}$ complex exhibited a monotonic trend and indicated that the complex formation was proportionally enhanced as the temperature increased. However, it slightly indicated a quasi sigmoidal feature around $43.79^{\circ} \mathrm{C}$ exhibiting a plateau on the higher temperature side. This behavior supports the fact that $\Delta \mathrm{S}$ or $\Delta \mathrm{H}$ may slightly depend on the temperature indicating that the conformational change of $A \beta_{12-28}$ during the complex formation with $\mathrm{CR}$ is gradual but not drastic at specific temperatures. Whereas CR-A $\beta_{1-40}$ complex formation should have involved the creation of bond formations and progressed as an enthalpy-driven process. Main interaction of the bonding with the CR is assumed to be electrostatic interaction where positively charged portion $\left({ }^{13}\right.$ Histidine, ${ }^{14}$ Hitidine, ${ }^{16}$ Lysine, or ${ }^{28}$ Lysine $)$ are interacting with negative sulfonate group in $\mathrm{CR}$. A hydrophilic portion $\left(A \beta_{1-17}\right)$ must be weakly bonded to $C R$ from backbone supporting the conjugation while $\mathrm{CR}$ is bonded with the sequence $A \beta_{17-22}$. This idea of backbone support is consistent with a finding of multiple binding sites suggested by the ITC experiments as described in section 4.2 of the Discussion.

While the spectroscopic approach provided a broad view of thermochemical values in the wide temperature range between 10 and $70^{\circ} \mathrm{C}$, the structural and thermochemical conditions of the complex is not the same over this temperature range. As an indication of this, there were two distinct regions suggesting different types of complexes centering at a specific temperature $T_{\mathrm{s}}=54.7$ \pm 0.2 and $34.8 \pm 0.2$ in van't Hoff plot for the CR-A $\beta_{1-40}$ and CR-A $\beta_{1-42}$ complexes, respectively (Figures 4(a) and (b)). On the other hand, the CR-A $\beta_{12-28}$ complex exhibited a single phase suggesting one major conformation over this temperature range (Figure 4(c)). The $\mathrm{A} \beta_{1-40}$ in an aqueous solution of $\mathrm{pH} 4.6-7.4$ at $4^{\circ} \mathrm{C}$ is reported to show a mostly unfolded and/or unusually folded conformation characteristic of an $A \beta$ monomer or dimer and a complete and rapid transition from $\beta$-strands to a coil form was reported at $15^{\circ} \mathrm{C}$ [33]. Then, an increase of $\beta$-sheet was confirmed as the temperature was raised up to $45^{\circ} \mathrm{C}$, which resulted in melting, and it reaches an ordered ensemble of conformations at $65^{\circ} \mathrm{C}$ which did not change up to $90^{\circ} \mathrm{C}$ [33-36]. The secondary structure at $45^{\circ} \mathrm{C}$ was however considered to be very similar to the spectrum at $25^{\circ} \mathrm{C}$ and indicated an absence of strong and persistent tertiary or quaternary structural interactions involving aromatic residues. Coincidentally, the specific temperature found in spectroscopic approach for CR- $A \beta_{1-40}$ complex $\left(\mathrm{T}_{\mathrm{s}}=54.7 \pm 0.2^{\circ} \mathrm{C}\right)$ was found to be in the middle of two characteristic temperatures $45^{\circ} \mathrm{C}$ and $65^{\circ} \mathrm{C}$. The specific temperature $\left(T_{s}\right)$ extracted in this study may correspond to the point where two different types of complexes are shifting its equilibrium from one to the other. It was striking that $\mathrm{CR}-\mathrm{A} \beta_{1-42}$ exhibited an opposite temperature dependence in thermochemical values as oppose to those of CR-A $\beta_{1-40}$, especially a negative value was seen only in the case of CR-A $\beta_{1-42}$ complexes formed below $34.8^{\circ} \mathrm{C}$, while most of the spectroscopic analysis resulted in a positive change in entropy. In addition, the heat of formation $\left(\Delta \mathrm{H}^{\circ}\right)$ of CR-A $\beta_{1-42}$ was under $34.8^{\circ} \mathrm{C}$ was largely endothermic leading the significantly positive Gibbs energy change $\left(\Delta G^{\circ}\right)$ for the complex formation. This is consistent with the formation of more precipitation at the lower temperature, indicating significant hydrophobic $\beta$-sheet formation of $A \beta_{1-42}$ at lower temperatures.

\subsection{Binding Sites of $C R$}

The ITC studies confirmed the existence of at least two binding sites in $A \beta_{1-40}$ for $C R$ dye. The two binding sites had distinctly different affinities for $\mathrm{CR}$, with binding constants separated by two orders of magnitude. Also, the ITC study showed that the lower affinity binding site saturates at an $\mathrm{r}$-value $(\mathrm{CR} / \mathrm{A} \beta$ mole ratio) of $\sim 0.25$, while the higher affinity site begins occupation above $r=0.25$ and appear to saturate at $r \sim 0.6$. This therefore implies that the higher affinity site is mostly absent in the early stages of complexation, otherwise the higher affinity site would have been occupied first if both sites are present at the onset of complexation. This can be explained by a conformational change as the first binding site was occupied, which then created a secondary binding site with higher affinity. This result agrees with studies by Kang and Han on the $A \beta_{1-40}$ binding 
abilities of several closely related analogs of Chrysamine $\mathrm{G}$ which is a compound that is structurally analogous to CR [37]. Here, the titration of CR into $A \beta$ in water may be at least partially responsible for a structural transition of $A \beta$ peptides to a higher order structure (presumably $\beta$-sheet) which binds CR itself with higher affinity. This presumably resulted in two distinctly different binding modes that appear "cooperative" in nature. A well accepted model for CR binding is an intercalation of $\mathrm{CR}$ into $A \beta$ which is proposed by several groups. $[23,38,39]$ In this model, the CR dye is proposed to intercalate between a pair of anti-parallel $\beta$-strands. Intercalation of CR may disrupt the four main-chain hydrogen bonds between the two $\beta$-strands by forming new hydrogen bonding partnerships between the nitrogen atoms of $\mathrm{CR}$ and the $\beta$-strands. The aromatic interaction between ${ }^{19}$ Phe in the $A \beta$ anti-parallel $\beta$-sheet and the two phenyl rings in $\mathrm{CR}$ is regarded as the most important interaction of the complex acting as an interface for the binding of $\mathrm{CR}$ in the $\beta$-chain. Furthermore, the ${ }^{16} \mathrm{Lys}$ in $\mathrm{A} \beta$ is considered to be positioned for electrostatic interaction with the charged sulfonate groups on CR.

Several other groups have observed a dual-binding mode for CR binding to $A \beta$ and have proposed a binding mechanism for each mode $[23,38]$. In these reports, the $\mathrm{CR}$ is proposed to lie either parallel (lower affinity site) or perpendicular (higher affinity site) to the-strands. In all these cases, the difference in binding constant between the two modes was essentially the same as that which we observe herein, i.e., two orders of magnitude. The two orders of magnitude difference in binding constant is due to differences in the stabilities of the two $\mathrm{CR}-\mathrm{A} \beta$ complexes. In the parallel binding mode, the $\mathrm{CR}$ is proposed to be intercalated between adjacent $\beta$ strands, while in the other mode, CR lies along the grooves on the surface of the $\beta$ fibrils, perpendicular to the main beta-strand direction, i.e., in the direction of the fibrils.

The binding of $C R$ to both $A \beta_{1-40}$ and $A \beta_{12-28}$ was enthalpically driven with highly negative $\Delta H$ and a much smaller negative $\Delta \mathrm{S}$ (Table 2). The $\Delta \mathrm{H}$ was -119.5 $\mathrm{kJ} / \mathrm{mol}$ (primary mode) and $-81.8 \mathrm{~kJ} / \mathrm{mol}$ (secondary mode), showing a greater enthalpic contribution for the primary mode. These values also agreed with the work by $\mathrm{Wu}$ and coworkers in which they found favorable enthalpic contributions for the binding of $\mathrm{CR}$ to GNNQQNY protofibrils that was $102.4 \mathrm{~kJ} / \mathrm{mol}$, falling between the values found in this study [38]. According to several models, the optimized spacing and orientation of certain $\mathrm{CR}$ groups relative to potential $\mathrm{A} \beta$ peptide sites suggest that these enthalpic contributions likely originates from: 1) electrostatic interaction between the two anionic sulfonates on $\mathrm{CR}$ and the cationic amino acids residues, and 2) hydrogen bonding between the two exocyclic $\mathrm{NH}_{2}$ and carbonyl groups in the peptide backbone $[23,38]$. While it is not always true, these interactions represent the most well accepted contributions to enthalpy [22,38] During the formation of the CR-A $\beta_{1-40}$ complex, the abovementioned two interactions must lead the stabilization of a complex, resulting in an exothermic process.

\subsection{Discrepancy in Thermal Values for forming CR-A $\beta$ Complex Between two Methods}

\section{1) Experimental condition}

The buffer environment was found to cause CR dye to bind $\mathrm{A} \beta$ monomers less favorably. Assuming that the complexation of CR dye is dominated by an electrostatic interaction, the complexation condition must be strongly affected by ionic strength created by the buffer salts. The weak basic condition may quench the positive charge present in the $A \beta_{1-40}$ and $A \beta_{1-42}$ monomers. As mentioned in a later section, the spectroscopic method detects complex under an equilibrium of complex formation rather than detecting the complex as it is formed. In the ITC method, the signals are proportional to the amount of complex produced as incremental amounts of $\mathrm{CR}$ dye are injected. Since the binding sites of $\mathrm{A} \beta$ was presumably closed under the buffer conditions, the amount of the complex corresponding to each injection were likely below the detection limit of the ITC instrument. On the other hand, in a cuvette (spectroscopic method) the complexes were formed under excess CR dye, and this condition is considered to produce enough complexes to be detected by the absorption band.

It is reasonable to speculate that charged side chain residues of $\mathrm{A} \beta$, (particularly three His residues: ${ }^{6} \mathrm{His}$, ${ }^{13} \mathrm{His}$, and ${ }^{14} \mathrm{His}$ ) are involved in deprotonation/ protonation reactions at different $\mathrm{pH}$ and salt conditions. Due to the electrostatic repulsion between $A \beta$ monomers in the charged hydrophilic region, the $\beta$-sheet structure can be enhanced as the ionic strength increases. This indicates that the presence of salts may cause significant difference in CR dye complexation with $A \beta$. This could also mean that the binding sites are blocked by the salt or by the folding of the $A \beta$ on itself. The binding sites or interaction with the outer ligands are known to be strongly affected by the counter ion (such as phosphate ion). $[24,39,40]$ It has been suggested that substitution of 19threonine $\left({ }^{19} \mathrm{Thr}\right)$ for phenylalanine $\left({ }^{19} \mathrm{Phe}\right)$ can abolish the plaque-forming competence of the mutant peptide, and that the mutant peptide is significantly less folded in aqueous buffer than the wild-type peptide [41].

2) Reaction path 
The process of complex formation in ITC and spectroscopic method provide different binding conditions of the $\mathrm{A} \beta$, and it must lead to different reaction path as shown in Figure 6. The ITC method detects the complex as it is "gradually" produced under an addition of CR dye (ligand). As CR was introduced incrementally into the $\mathrm{A} \beta$ binding sites, calorimetric response was monitored as the binding of $\mathrm{CR}$ to $\mathrm{A} \beta$ took place. In this situation, the concentration of CR should have started from the saturation value. On the other hand, the spectroscopic method possesses a maximum number of complex produced under an equilibrium. While ligands molecules could exceed the available binding sites, the residual unbounded $\mathrm{CR}$ could push the equilibrium toward the formation of complex. Two different path of the complex formation between ITC and spectroscopic
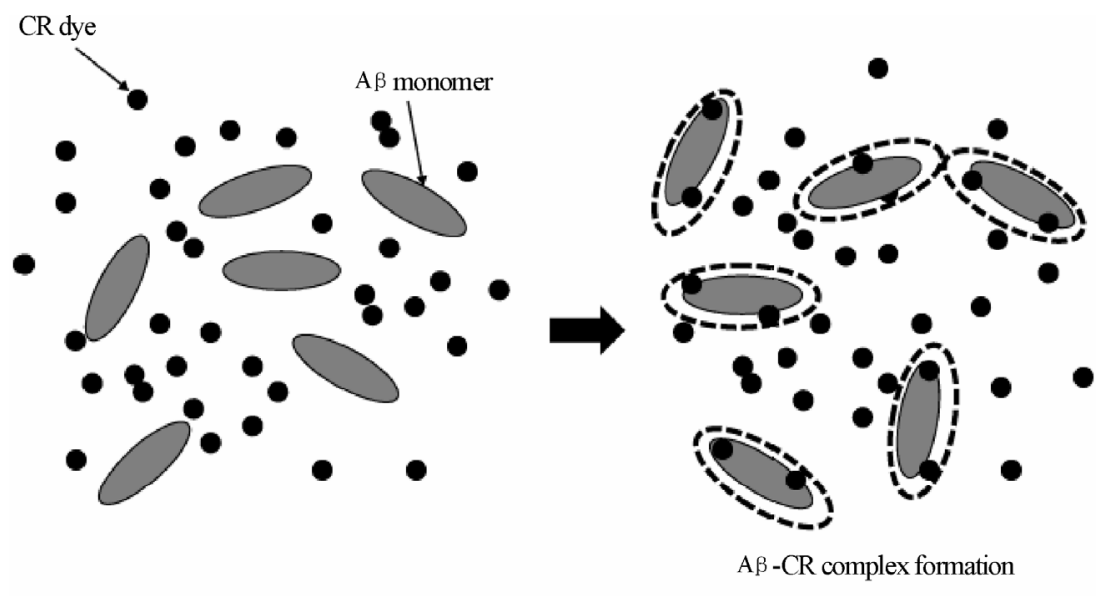

Detectable AB-CR complex

(a)

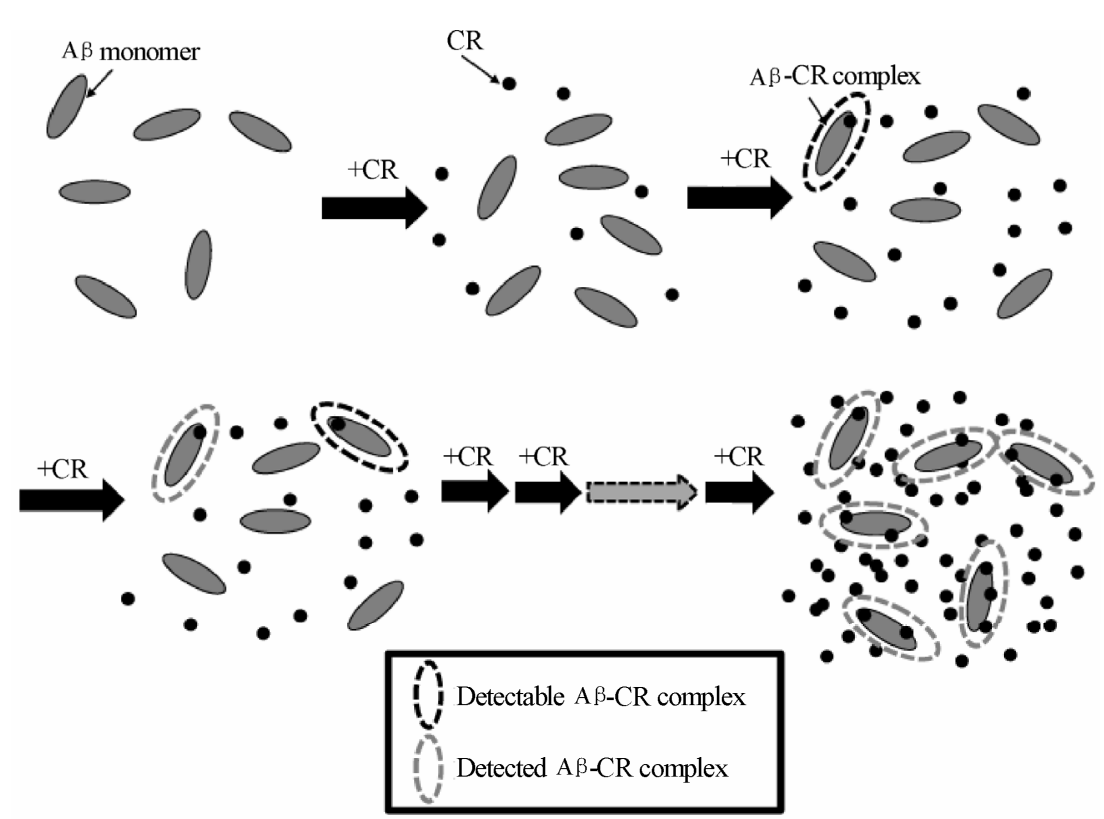

(b)

Figure 6. Sketch of proposed formation of CR-A $\beta$ complex in (a) spectroscopic method and (b) ITC. In a spectroscopic method, the complex formed under an equilibrium (the situation shown on the right) is monitored by absorption spectroscopy. For the ITC experiment, the determined amount $\mathrm{CR}$ dye is injected and the resulted complex formation is monitored. The injection of the $\mathrm{CR}$ is continued until binding sites are saturated. 
method naturally cause two different reaction path. Also different solvent condition (buffer versus water) must create different reaction paths resulting different thermal properties of the formed CR-A $\beta$ complex.

In conclusion, both spectroscopic and calorimetric methods were used to probe the interaction of $\mathrm{CR}$, a known amyloid peptide specific dye, to the most causative sequences of $A \beta$ peptides and have found some interesting characteristics about the complexation process. By utilizing spectroscopic and ITC method, two different binding environment between $\mathrm{A} \beta$ and $\mathrm{CR}$ were introduced and successfully monitored two different reaction path of complex formation. As the search for effective treatment for diseases linked to amyloid peptide aggregation continues, compounds that binds specifically to amyloids peptides and regulate its aggregate behavior must be seen as a promising option for both the therapeutic treatment and detection of these harmful peptide aggregates. There is no doubt that given the inherent potential, insights gained from this work can bring us closer to a molecular level understanding of how $C R$ interacts with its $A \beta$ peptides targets and may have far reaching implications in the rationale design of novel therapeutic drugs in this class that possess more efficacy against amyloid fibril formation. This can ultimately lead to the treatment of amyloid-plaque related diseases such as Alzheimer's disease.

\section{ACKNOWLEDGEMENTS}

A generous contribution from The SUNY Geneseo Foundation is greatly acknowledged. We thank Tonya Gilbert and Colleen Clark for their work at the initial stage of this project. We are grateful for valuable suggestions to this manuscript from Nicholas Miravalle and Nicole Briglio at SUNY Geneseo.

\section{REFERENCES}

[1] Selko, D.J. (1991) The molecular pathology of Alzheimer's disease. Neuron, 6, 487-498.

[2] Terry, R.D. (1994) Neuropathological changes in Alzheimer disease. Progress in Brain Research, 101, 383390.

[3] Glenner, G.G. and Wong, C.W. (1984) Alzheimer's disease: initial report of the purification and characterization of a novel cerebrovascular amyloid protein. Biochemical and Biophysical Research Communications, 120, 885890.

[4] Brion, J.P. (1992) The pathology of the neuronal cytoskeleton in Alzheimer's disease. Biochimica et Biophysica Acta, 1160, 134-142.

[5] Yamaguchi, H., Nakazato, Y., Hirai, S., Shoji, M. and Harigaya, Y. (1989) Electron micrograph of diffuse plaques. Initial stage of senile plaque formation in the Alzheimer brain. The American Journal of Pathology, 135, 593-597.
[6] Thirumalai, D., Kimov, D.K. and Dima, R.I. (2003) Emerging ideas on the molecular basis of protein and peptide aggregation. Current Opinion in Structural Biology, 13, 146-159.

[7] Rochet, J.C. and Lansbury, P.T. (2000) Amyloid fibrillogenesis: themes and variations. Current Opinion in Structural Biology, 10, 60-68.

[8] Dobson, C.M. (1999) Protein misfolding, evolution and disease. Trends in Biochemical Sciences, 24, 329-332.

[9] Kelly, J.W. (1998) The alternative conformations of amyloidogenic proteins and their multi-step assembly pathways. Current Opinion in Structural Biology, 8, 101106.

[10] Hashimoto, M., Rockenstein, E., Crews, L. and Masliah, E. (2003) Role of protein aggregation in mitochondrial dysfunction and neurodegeneration in Alzheimer's and Parkinson's diseases. Neuromolecular Medicine, 4, 2135.

[11] Lorenzo, A.R., Weir, B. and Yanker, B.A. (1994) Pancreatic islet cell toxicity of amylin associated with type-2 diabetes mellitus. Nature, 368, 756-760.

[12] Hardy, J. and Selkoe, D.J. (2002) The amyloid hypothesis of Alzheimer's disease: progress and problems on the road to therapeutics. Science, 297, 353-356.

[13] Bucciantini, M., Calloni, G., Chiti, F., Formigli, L., Nosi, D., Dobson, C.M. and Stefani, M. (2004) Prefibrillar amyloid protein aggregates share common features of cytotoxicity. The Journal of Biological Chemistry, 279, 31374-31382.

[14] Rogers, J., Cooper, N.R., Webster, S., Schultz, J., McGeer, P.L., Styren, S.D., Civin, W.H., Brachova, L., Bradt, B. and Ward, P. (1992) Complement activation by beta-amyloid in Alzheimer disease. Proceedings of $\mathrm{Na}$ tional Academy of Science of the United States of America, 89, 10016-10020.

[15] Joachim, C.L., Mori, H. and Selkoe, D.J. (1989) Amyloid beta-protein deposition in tissues other than brain in Alzheimer's disease. Nature, 341, 226-230.

[16] Cairo, C.W., Strzelec, A., Murphy, R.M. and Kiessling, L.L. (2002) Affinity-based inhibition of ß-amyloid toxicity. Biochemistry, 41, 8620-8629.

[17] Rudyk, H., Vasiljevic, S., Hennion, R.M., Birkett, C.R., Hope, J. and Gilbert, I.H. (2000) Screening Congo red and it is analogues for their ability to prevent the formation of PrP-res in scrapie-infected cell. Journal of General Virology, 81, 1155-1164.

[18] Lee, V.M.Y. (2002) Amyloid binding ligands as Alzheimer's disease therapies. Neurobiolgy of Aging, 23, 1039-1042.

[19] Caughey, B., Ernst, D. and Race, R.E. (1993) Congo red inhibition of scrapie agent replication. Journal of Virology, 67, 6270-6272.

[20] Caughey, B. and Race, R.E. (1992) Potent inhibition of scrapie-associated $\operatorname{PrP}$ accumulation by Congo red. Journal of Neurochemistry, 59, 768-771.

[21] Klunk, W.E., Jacob, R.F. and Mason, R.P. (1999) Quantifying Amyloid $B$ Peptide $(A \beta)$ aggregation using the Congo red-A $\beta$ (CR-A 3 ) spectrophotometric assay. Analytical Biochemistry, 266, 66-76.

[22] Klunk, W.E., Pettegrew, J.W. and Abraham, D.J. (1989) Quantitative evaluation of Congo red binding to amyloidlike proteins with a ß-pleated sheet conformation. Jour- 
nal of Histochemistry and Cytochemistry, 37, 12731281.

[23] Carter, D.B. and Chou, K.C. (1998) A model for structure-dependent binding of Congo red to Alzheimer ß-amyloid fibrils. Neurobiology of Aging, 19, 37-40.

[24] Yokoyama, K. and Welchons, D.R. (2007) The conjugation of amyloid beta protein on the gold colloidal nanoparticles' surface. Nanotechnology, 18, 105101-105107.

[25] Yokoyama, K., Briglio, N.M., Sri Hartati, D., Tsang, S.M.W., MacCormac, J.E. and Welchons, D.R. (2008) Nano-scale Size Dependence in the Conjugation of Amyloid Beta and Ovalbumin Proteins on the Surface of Gold Colloidal Particles. Nanotechnology, 19, 375101375108.

[26] Yokoyama, K., Cho, H., Cullen, S.P., Kowalik, M., Briglio, N.M., Hoops, H.J., Zhao, Z. and Carpenter, M.A. (2009) Microscopic Investigation of Reversible Nanoscale Surface Size Dependent Protein Conjugation. International Journal of Molecular Science, 10, 23482366.

[27] Yokoyama, K. (2010) Nanoscale Protein Conjugation. In: Advances in Nanotechnology Vol. 1 (Chen, E.J. and Peng, N., eds.), Nova Science Publishing.

[28] Yokoyama, K., Gaulin, N.B., Cho, H. and Briglio, N.M. (2010) Temperature Dependence of Conjugation of Amyloid Beta Peptide on the Gold Colloidal Nanoparticles". Journal of Physical Chemistry A, 114, 1521-1528.

[29] Harper, J.D. and Lansbury, P.T. (1997) Models of amyloid seeding in Alzheimer's disease and scrapie: Mechanistic truths and physiological consequences of the timedependent solubility of amyloid proteins. Annual Reviews of Biochemistry, 66, 385-407.

[30] Harper, J.D., Lieber, C.M. and Lansbury, P.T. (1997) Atomic force microscopic imaging of seeded fibrilformation and fibril branching by the Alzheimer's disease amyloid-b protein. Chemistry and Biology, 4, 951-959.

[31] Harper, J.D., Wong, S., Lieber, C.M. and Lansbury, P.T. (1997) Observation of metastable Ab amyloid protofibrils by atomic force microscopy. Chemistry and Biology, 4, 119-125.

[32] Edelhoch, H. (1967) Spectroscopic determination of tryptophan and tyrosine in proteins. Biochemistry, 6, 1948-
1954.

[33] Gursky, O. and Aleshkov, S. (2000) Temperatureependent beta-sheet formation in beta-amyloid $A \beta(1-40)$ peptide in water: uncoupling beta-structure folding from aggregation. Biochimica et Biophysica Acta, 1476, 93102.

[34] Perczel, A., Park, K. and Fasman, G.D. (1992) Analysis of the circular dichroism spectrum of proteins using the convex constraint algorithm: A practical guide. Analytical Biochemistry, 203, 83-93.

[35] Brahms, S. and Brhams, J. (1980) Determination of protein secondary structure in solution by vacuum ultraviolet circular dichroism. Journal of Molecular Biology, 138, 149-178.

[36] Yang, J.D., Wu, C.S.C. and Martinez, H.M. (1986) Calculation of protein conformation from circular dichroism Methods in Enzymology, 130, 208-269.

[37] Kang, J. and Han, K. (2001) The amide derivatives of chrysamine $\mathrm{G}$ bind to the beta-amyloid fibril. Bulletin of the Korean Chemical Society, 22, 1065-1066.

[38] Wu, C., Lei, H.X., Wang, Z.X., Zhang, W. and Duan, Y. (2007) Dual binding modes of Congo red to amyloid protofibril surface observed in molecular dynamics simulations. Journal of the American Chemical Society, 129, 1225-1232.

[39] Turrell, W.G. and Finch, J.T. (1992) Binding of the dye Congo red to the amyloid protein pig insulin reveals a novel homology amongst amyloid-forming peptide sequences. Journal of Molecular Biology, 227, 1205-1223.

[40] McLaurin, J., Franklin, T., Zhang, X., Deng, J.P. and Fraser, P.E. (1999) Interactions of Alzheimer amyloid- $\beta$ peptides with glycosaminoglycans-effects on fibril nucleation and growth. European Journal of Biochemistry, 266, 1101-1110.

[41] Esler, W.P., Stimson, E.R., Ghilardi, J.R., Lu, Y.A., Felix, A.M., Vinters, H.V., Mantyh, P.W., Lee, J.P. and Maggio, J.E. (1996) Point substitution in the central hydrophobic cluster of a human b-amyloid congener disrupts peptide folding and abolishes plaque competence. Biochemistry, 35, 13914-13921.

\section{List of Abbreviations}

$\mathrm{AD}=$ Alzheimer's disease, $\mathrm{A} \beta=$ amyloid beta, $\mathrm{CR}=$ Congo red dye, $\mathrm{PBS}=$ phosphate-buffered saline, $\mathrm{ITC}=$ isothermal titration calorimetry 